\title{
Low-Isostatic-Press Sintering of Iron Alloy Powder
}

\author{
Hidekazu Sueyoshi ${ }^{1}$, Shigeru Uchida ${ }^{2}$, Takeru Miyanowaki ${ }^{1, *}$, \\ Keita Kume ${ }^{1, *}$ and Ryo Kurose ${ }^{1, *}$ \\ ${ }^{1}$ Graduate School of Science and Engineering, Kagoshima University, Kagoshima 890-0065, Japan \\ ${ }^{2}$ Technical Development Bureau, Nippon Steel Corporation, Futtsu 293-8511, Japan
}

An end-sealed thin stainless-steel pipe in which a high-speed steel compact was inserted was evacuated with a vacuum pump during heating at an elevated temperature using an atmosphere furnace. The sintering behavior of this low isostatic press sintering (LIPS) was examined in detail. The compact is subjected to isostatic compression stress through the deformation of stainless-steel owing to atmospheric pressure. As the gas pressure in the stainless-steel pipe is low (about $2 \times 10^{-2} \mathrm{~Pa}$ ), as the sintering temperature is high $(1573 \mathrm{~K})$, and as the holding time is long ( $4 \mathrm{~h}$ ), densification and hardness of the LIPS compact are large (about $H_{\mathrm{v}} 640$ ). This is because the decomposition of FeO film formed on the surface of the as-received powder is vigorous at low gas pressure in the stainless-steel pipe and high LIPS temperature, the degree of powder contact increases because of a large plastic flow of powder particles owing to both the degradation of the strength of high-speed steel powder at a high temperature and the compression stress caused by atmospheric pressure, and Fe diffusion is encouraged by heating at high temperature for a long time. At an early stage of LIPS, pores of the center of the LIPS compact diffuse into the surface, resulting in the reduction of densification near the surface. However, by holding for a long time, the LIPS compact that has high densification from the surface to the center is obtained because of encouragement of Fe diffusion. Under optimum LIPS conditions, it is possible to obtain a homogeneous LIPS compact which has porosity and hardness levels equivalent to those of the HIP compact. [doi:10.2320/matertrans.47.2828]

(Received May 12, 2006; Accepted September 22, 2006; Published November 15, 2006)

Keywords: powder metallurgy, low-isostatic-press sintering, iron alloy, oxide film, densification

\section{Introduction}

Continuous-ceramic-fiber-reinforced metal is a metal matrix composite reinforced with high-strength continuous ceramic fiber. Aluminum and titanium have a low density. Therefore, many aluminum or titanium matrix composites have been developed as light materials. ${ }^{1-13)}$ However, few studies have been conducted so far on the iron matrix composite because of its high melting point. We examined the processing of continuous ceramic fiber/iron alloy composites by powder metallurgy. It was found that the continuous ceramic fiber/iron alloy composite in which fibers are uniformly dispersed can be produced by choosing an appropriate combination of fiber diameter and the particle size of iron alloy powder, using a suitable fiber-dispersion method, and by hot isostatic pressing (HIP) or hot pressing (HP) at optimum temperature and pressure. ${ }^{14,15)}$ However, an adequate degasification is required for a HIP capsule. In addition, HIP is inapplicable to the composite system that reaction gas generates during sintering. On the other hand, the number of degrees of composite shape variance is small in HP. The composite produced by HP is anisotropic with respect to mechanical properties. In HIP and HP, a large pressure generator and a high-pressure vessel or refractory mold are required for manufacturing a large product. In order to achieve low manufacturing costs, the CAP (Consolidation by Atmospheric Pressure) process has been developed. ${ }^{16)}$ In this process, the obtained compact containing small remnant pores (relative density: 95 to $99 \%$ ) is then followed by hot working. In the CAP process, a sealed glass capsule is used. Therefore this process is unsuitable for the composite system that reaction gas generates during heating. Thus the CAP process is similar to HIP except for the low isostatic pressure (atmospheric pressure).

*Graduate Student, Kagoshima University
In order to solve the problems mentioned above, we examined a new sintering method in which an end-sealed thin metal pipe in which a green compact was inserted was evacuated with a vacuum pump during heating at an elevated temperature using an atmosphere furnace. The results revealed the following; (1) the compact is subjected to isostatic compression stress through the deformation of a thin metal pipe owing to atmospheric pressure at an elevated temperature, (2) sintering becomes feasible for the composite system that reaction gas generates during heating, and (3) the large pressure generator and high-pressure vessel are unnecessary for manufacturing a large product. This method is a combination of CAP process and vacuum sintering (VS). We refer to this method as "low-isostatic-press sintering (LIPS)". There have been few reports regarding LIPS. We examined the LIPS behavior of iron alloy powder to obtain the fundamental data on preparation of ceramic fiber/iron alloy composite by LIPS. In the present paper, the LIPS behavior of iron alloy powder is explained in detail.

\section{Experimental Procedure}

High-speed steel (HSS) powder (Mitsubishi Metal Co., Ltd.: MIREX; mean particle size: $13.4 \mu \mathrm{m}$; true density: 7.93 $\mathrm{Mg} / \mathrm{m}^{3}$ ) was used as iron alloy. Figure 1 shows a schematic view of an end-sealed thin metal pipe. A part of the stainlesssteel pipe was machined to the thickness of $0.5 \mathrm{~mm}$, followed by TIG welding. HSS green compact prepared under the uniaxial die compaction pressure of $245 \mathrm{MPa}$ was inserted into this stainless-steel pipe, followed by LIPS.

Figure 2 shows a schematic diagram of LIPS. The stainless-steel pipe containing a green compact was evacuated with a vacuum pump during heating at an elevated temperature using an atmosphere furnace. Two types of vacuum pump, a rotary pump (RP) and a diffusion pump (DP), were used. The gas pressure in the stainless-steel pipe 


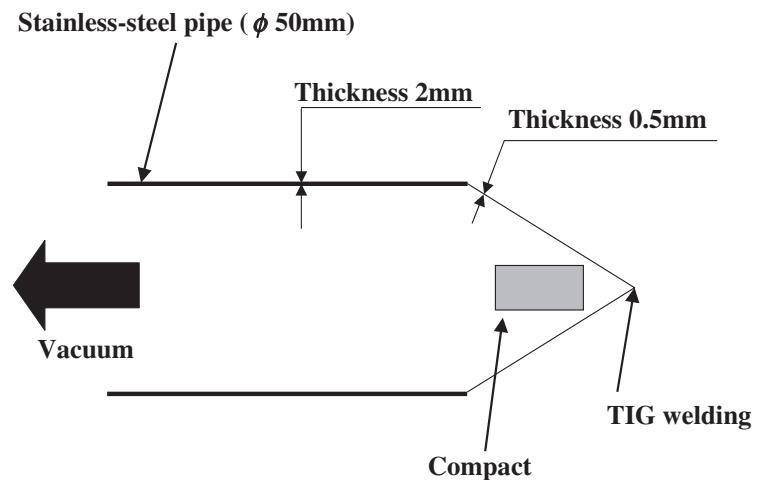

Fig. 1 Schematic view of an end-sealed thin metal pipe.

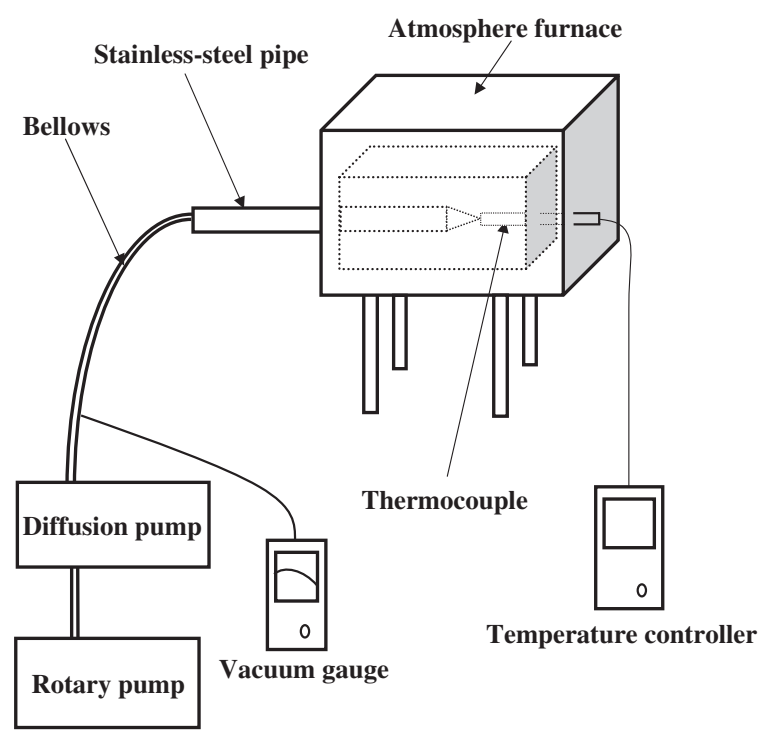

Fig. 2 Schematic diagram of LIPS.

was continuously measured using a vacuum gauge during LIPS.

A stainless-steel mold in which HSS powders were packed was degassed at $823 \mathrm{~K}$ in vacuum and then sealed by TIG welding. The stainless-steel capsule was HIPed at $1273 \mathrm{~K}$ for $2 \mathrm{~h}$ under the pressure of $98 \mathrm{MPa}$ (Kobe Steel Co., Ltd.: Dr. HIP). In vacuum sintering, HSS green compact prepared under the uniaxial die compaction pressure of $245 \mathrm{MPa}$ was heated at $1523 \mathrm{~K}$ for $4 \mathrm{~h}$ without pressing in vacuum (with DP).

The microstructures of the cross section of the sintered compact were examined using a scanning electron microscope (SEM). The area fraction of a pore in the cross section of the sintered compact was measured using an image analyzer (Nireco Co., Ltd.: Luzex-FS). The Vickers hardness of the cross section of the sintered compact was measured along radial and axial directions.

In the present study, HSS powder produced by water atomization was used. Therefore, The powder may have an Fe oxide film on the surface. In order to examine the influence of the oxide film on LIPS behavior, X-ray photoelectron spectroscopy (XPS) analysis was carried out on both the as-received powder and the LIPS compact.

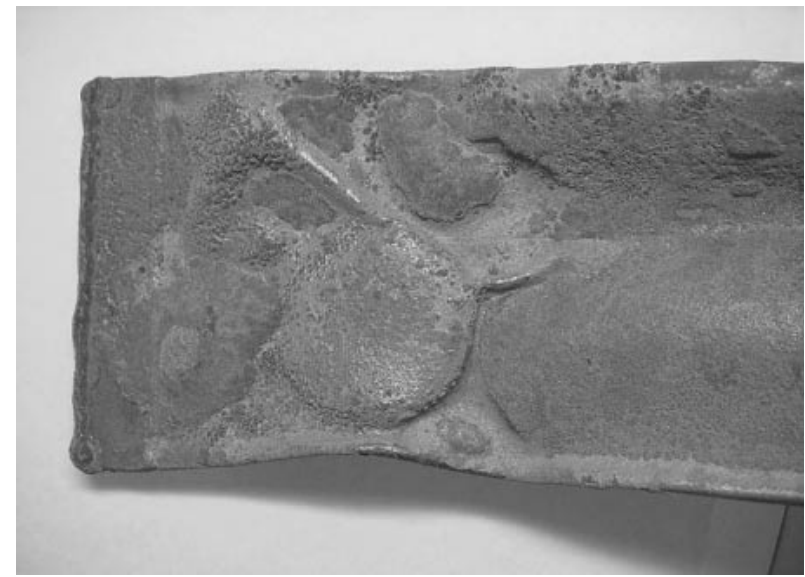

Fig. 3 Appearance of the stainless-steel pipe after LIPS.

\section{Results and Discussion}

Figure 3 shows the appearance of the stainless-steel pipe after LIPS (sintering at $1473 \mathrm{~K}$ for $4 \mathrm{~h}$ with DP). The compact is closely covered with stainless steel. This suggests that the compact is subjected to isostatic compression stress through the deformation of stainless steel owing to atmospheric pressure $(0.1 \mathrm{MPa})$.

Figure 4 shows secondary electron (SE) images of the center of the cross section in LIPS compacts. A white part is carbide, a black part is a pore. In the LIPS compact prepared by sintering at $1473 \mathrm{~K}$ for $4 \mathrm{~h}$ with $\mathrm{RP}$, large pores appear as shown in Fig. 4(a). When the sintering temperature is raised up to $1523 \mathrm{~K}$, large pores disappear as shown in Fig. 4(b). However micro-pore remains partially. In the LIPS compact prepared by sintering at $1473 \mathrm{~K}$ for $4 \mathrm{~h}$ with $\mathrm{DP}$, a few micropores are observed although large pores disappear (Fig. 4(c)). When the temperature is raised up to $1523 \mathrm{~K}$, few micropores are observed as shown in Fig. 4(d). These results suggest that densification of the LIPS compact depends upon evacuation method and sintering temperature.

Figure 5 shows the relationships between the hardness at the center of the cross section in the sintered compact and sintering temperature. In the LIPS compact prepared by sintering at $1373 \mathrm{~K}$ with DP, the densification is very low, resulting in low hardness $\left(H_{\mathrm{v}} 100\right)$. The hardness of the LIPS compact increases with sintering temperature. When sintering temperature exceeds $1498 \mathrm{~K}$, the hardness increases abruptly once but increases slowly thereafter. Although the hardness change for the LIPS compact with RP is similar to that for the LIPS compact with DP, the hardness of the former is lower than that of the latter. In the VS compact, a large cavity was observed. This is because a large cavity existing in the green compact remains as no-sintered region in the sintered compact owing to VS without pressing. Therefore, the hardness of a large-cavity-free region is plotted in Fig. 5. The hardness of this region is lower than that of the LIPS compact with DP. On the other hand, the hardness of the HIP compact is very high.

Figure 6 shows the relationships between the area fraction of pores at the center of the cross section in the sintered compact and sintering temperature. In the LIPS compact with 
(a)

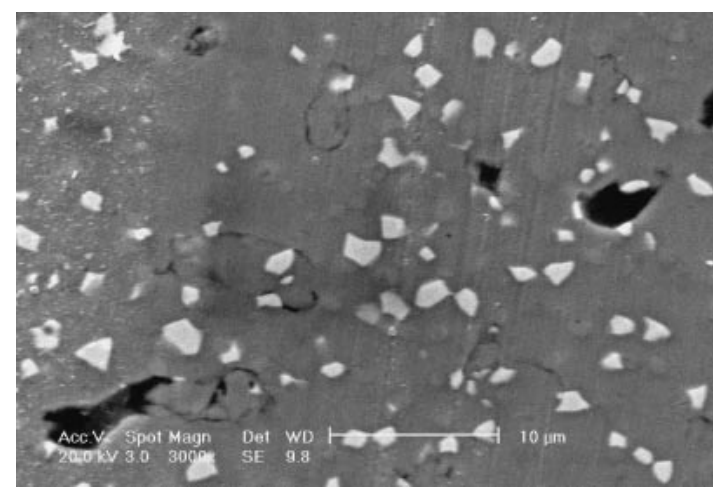

(b)

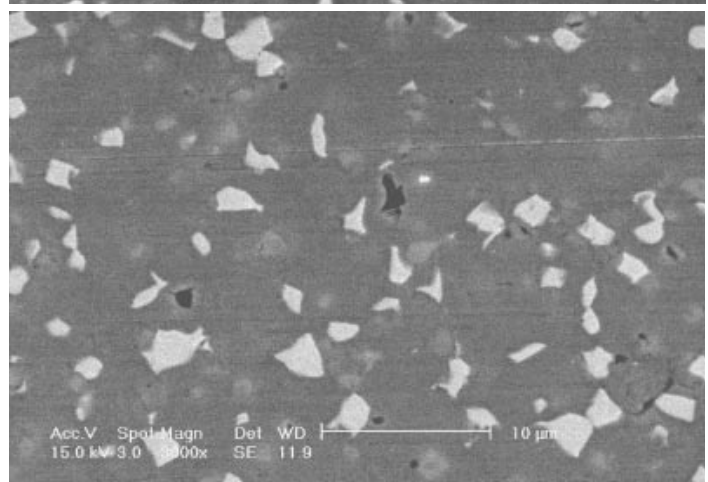

(c)

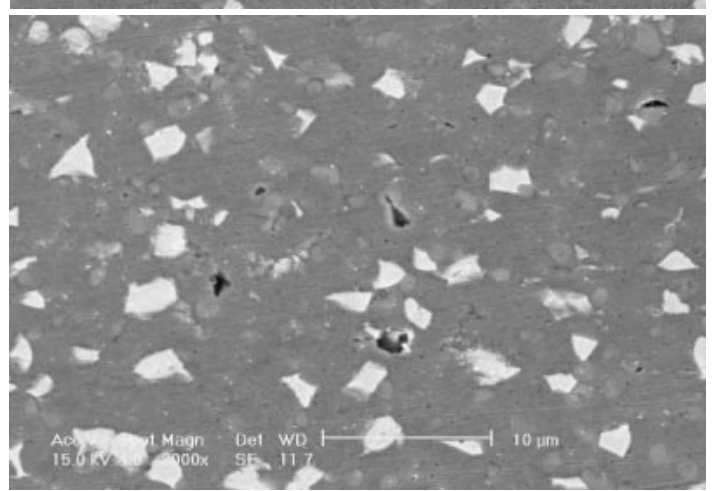

(d)

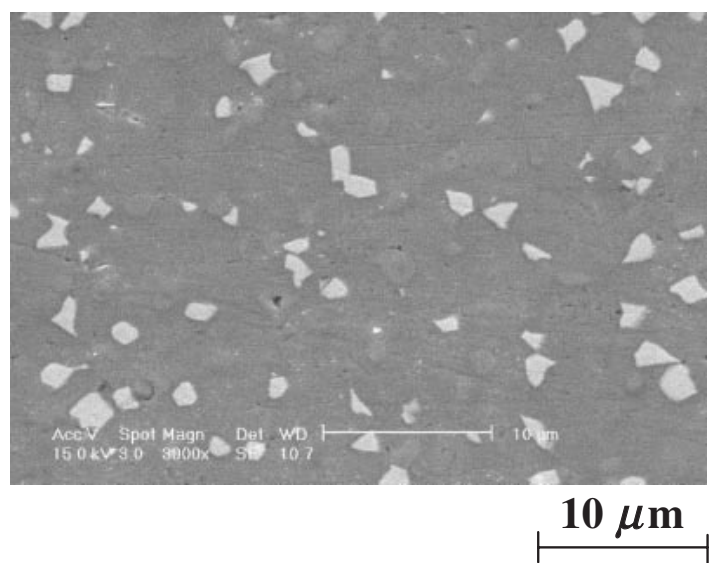

Fig. 4 SE images of the center of the cross section in the LIPS compacts. (a) at $1473 \mathrm{~K}$ for $4 \mathrm{~h}$ with $\mathrm{RP}$, (b) at $1523 \mathrm{~K}$ for $4 \mathrm{~h}$ with $\mathrm{RP}$, (c) at $1473 \mathrm{~K}$ for $4 \mathrm{~h}$ with $\mathrm{DP},(\mathrm{d})$ at $1523 \mathrm{~K}$ for $4 \mathrm{~h}$ with $\mathrm{DP}$.

DP, the area fraction of pores decreases with increasing sintering temperature. However, it decreases slowly when sintering temperature exceeds $1523 \mathrm{~K}$. Although the change in the area fraction of pores for the LIPS compact with RP is similar to that for the LIPS compact with DP, the area fraction of pores for the former is larger than that for the

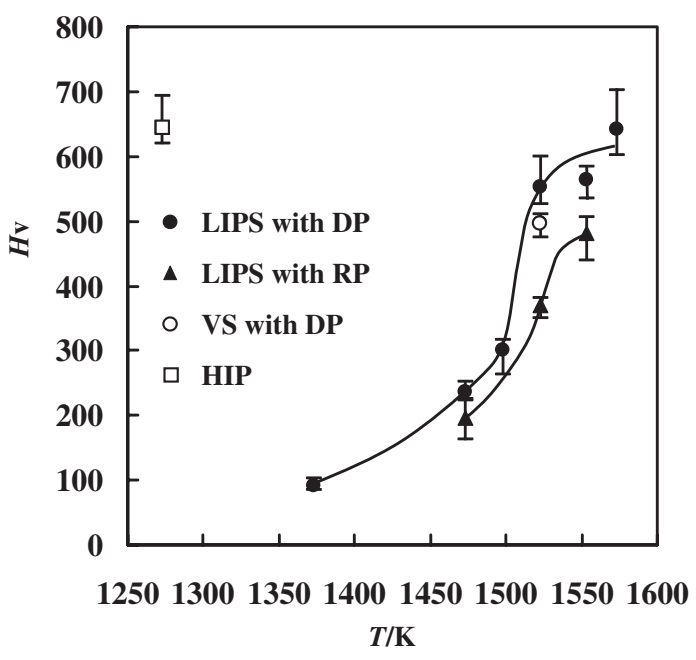

Fig. 5 Relationships between the hardness at the center of the cross section in the sintered compact and sintering temperature.

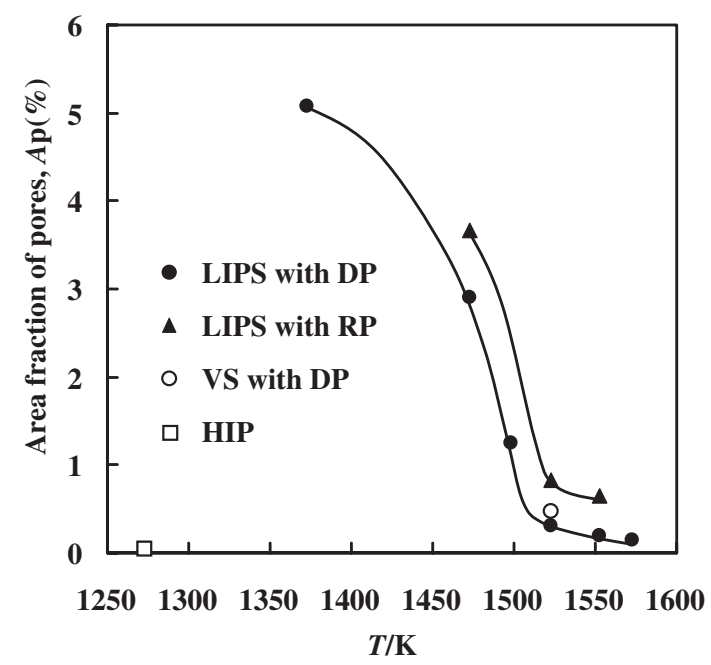

Fig. 6 Relationships between the area fraction of pores at the center of the cross section in the sintered compact and sintering temperature.

latter. The area fraction of pores of the large-cavity-free region in the VS compact is larger than that of the LIPS compact with DP. The HIP compact is found to be nearly full-density.

Figure 7 shows the relationship between the area fraction of pores and the hardness at the center of the cross section in the sintered compact. The hardness increases with decreasing area fraction of pores, regardless of sintering method. This suggests that hardness depends largely on porosity rather than the matrix microstructure and carbide. Thus, under optimum LIPS conditions, it is possible to obtain a good sintered compact which has porosity and hardness levels equivalent to those of the HIP compact.

Figure 8 shows an SE image of the center of the cross section in the LIPS compact prepared by sintering at $1523 \mathrm{~K}$ for $1 \mathrm{~h}$ with DP. As mentioned above, the LIPS compact in which the pores are entirely absent was achieved by sintering at $1523 \mathrm{~K}$ for $4 \mathrm{~h}$ with $\mathrm{DP}$, resulting in high hardness (Figs. 4(c) and 5). In the holding time of $1 \mathrm{~h}$, a few pores 


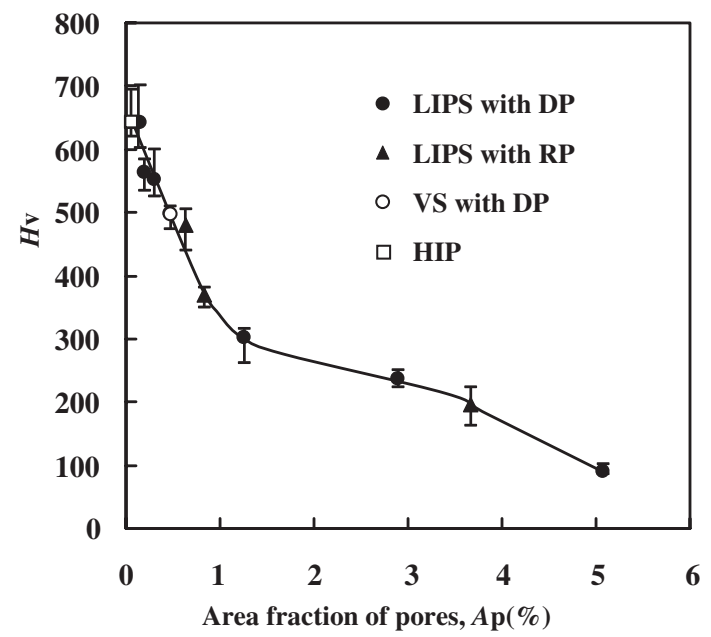

Fig. 7 Relationship between the area fraction of pores and the hardness at the center of the cross section in the sintered compact.

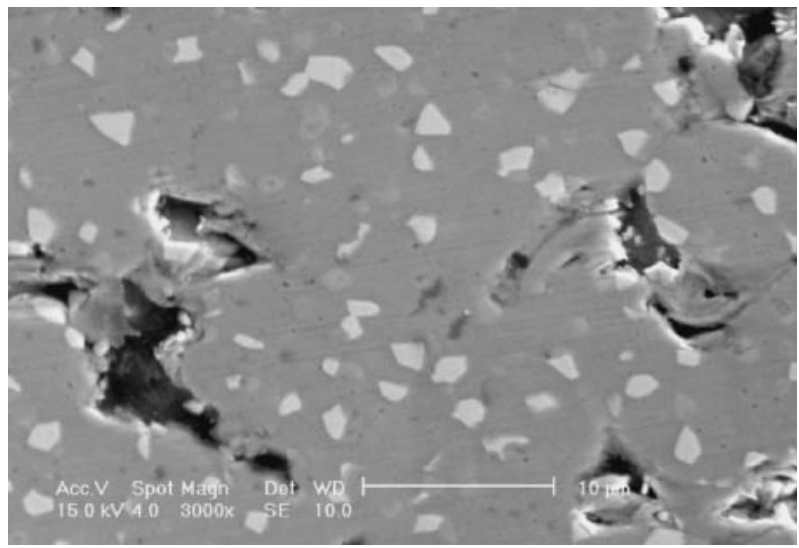

$10 \mu \mathrm{m}$

Fig. 8 SE image of the center of the cross section in the LIPS compact prepared by sintering at $1523 \mathrm{~K}$ for $1 \mathrm{~h}$ with DP.

(black parts) appear as shown in Fig. 8, resulting in low hardness.

Generally, at the early stage of sintering, surface diffusion or evaporation-condensation is the most important process. Thereafter, grain boundary diffusion or volume diffusion is the governing factor. We can roughly estimate diffusion distance by

$$
x=(D t)^{1 / 2},
$$

where $x, D$ and $t$ are the diffusion distance, diffusivity and holding time, respectively. From the value of $D$ for $\mathrm{Fe}$ diffusion $^{17)}$ and eq. (1), the $\mathrm{Fe}$ diffusion distance due to volume diffusion can be calculated to be about $8 \mu \mathrm{m}$ in the case of sintering at $1523 \mathrm{~K}$ for $1 \mathrm{~h}$ and about $16 \mu \mathrm{m}$ in the case of sintering at $1523 \mathrm{~K}$ for $4 \mathrm{~h}$. Under the latter condition, the Fe diffusion distance suffices for densification because the mean particle size of HSS powder $(13.4 \mu \mathrm{m})$ is smaller than that distance. The results in which the LIPS compact in which the pores are entirely absent was achieved by sintering at $1523 \mathrm{~K}$ for $4 \mathrm{~h}$ (Fig. 4(c)), while the compact having a few

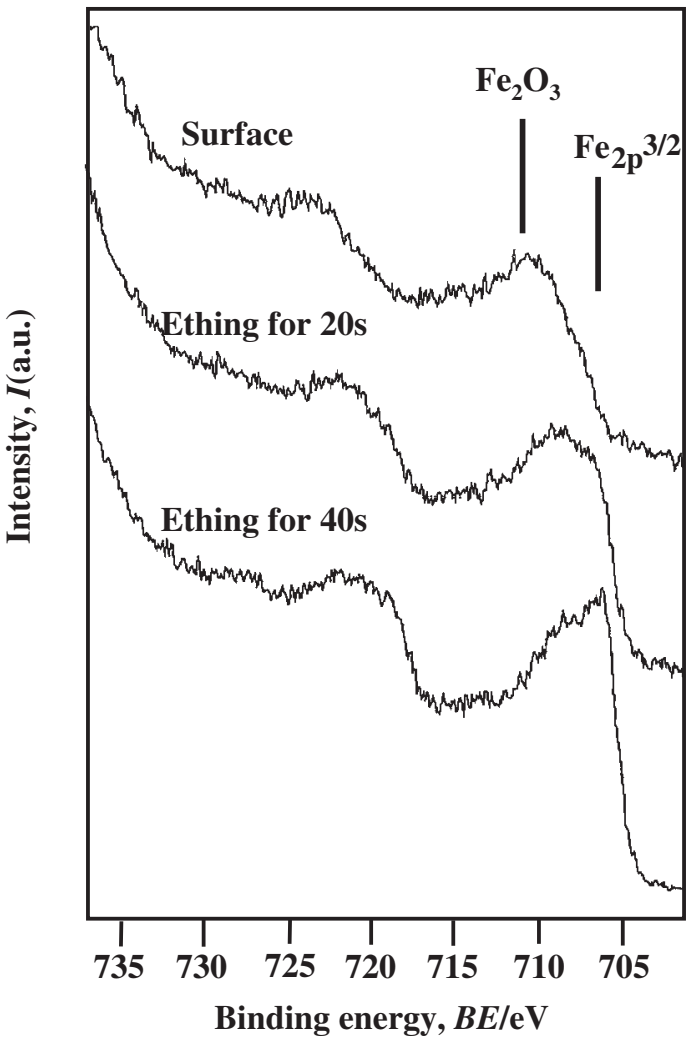

Fig. 9 XPS spectra of as-received HSS powder.

pores was achieved by sintering at $1523 \mathrm{~K}$ for $1 \mathrm{~h}$ (Fig. 8) is explainable in terms of this diffusion behavior. In the case of sintering at $1473 \mathrm{~K}$ for $4 \mathrm{~h}, \mathrm{Fe}$ diffusion distance becomes about $10 \mu \mathrm{m}$. This corresponds to that in the case of sintering at $1523 \mathrm{~K}$ for $2 \mathrm{~h}$. The result in which the LIPS compact prepared by sintering at $1473 \mathrm{~K}$ for $4 \mathrm{~h}$ has a low hardness (Fig. 5) is thought to be due to a few remaining pores that results from insufficient $\mathrm{Fe}$ diffusion.

As shown in Fig. 6, the effect of DP on densification is large as compared with that of RP. Figure 9 shows the XPS spectra of as-received HSS powder. It is found from the Fe spectrum of the surface that the surface of HSS powder consists of $\mathrm{Fe}$ oxide. In the XPS spectrum after etching for $40 \mathrm{~s}$, a well-defined peak of metallic Fe appears in addition to the peak of $\mathrm{Fe}$ oxide. Also, the intensity of the peak of metallic Fe increases with depth from the surface. From Fig. 9, the thickness of Fe oxide seems to be several ten nm.

Figure 10 shows the XPS spectrum of the center of the cross section in the LIPS compact prepared by sintering at $1523 \mathrm{~K}$ for $4 \mathrm{~h}$ with DP. In the Fe spectrum, the peak of $\mathrm{Fe}$ oxide is not evidently as compared with the defined peak of metallic Fe. This suggests that the decomposition of Fe oxide occurs during LIPS.

In LIPS and VS with DP, the gas pressure in the stainlesssteel pipe rose immediately after heating because of the evaporation of the binder used to form the green compact. Thereafter the gas pressure fell down to about $2 \times 10^{-2} \mathrm{~Pa}$ with binder disappearance. The gas pressure rose also in the temperature range from 1073 to $1173 \mathrm{~K}$ because of the desorption of the free radical $\mathrm{OH}$ from the HSS powder surface. When the temperature exceeded $1473 \mathrm{~K}$, a marked 


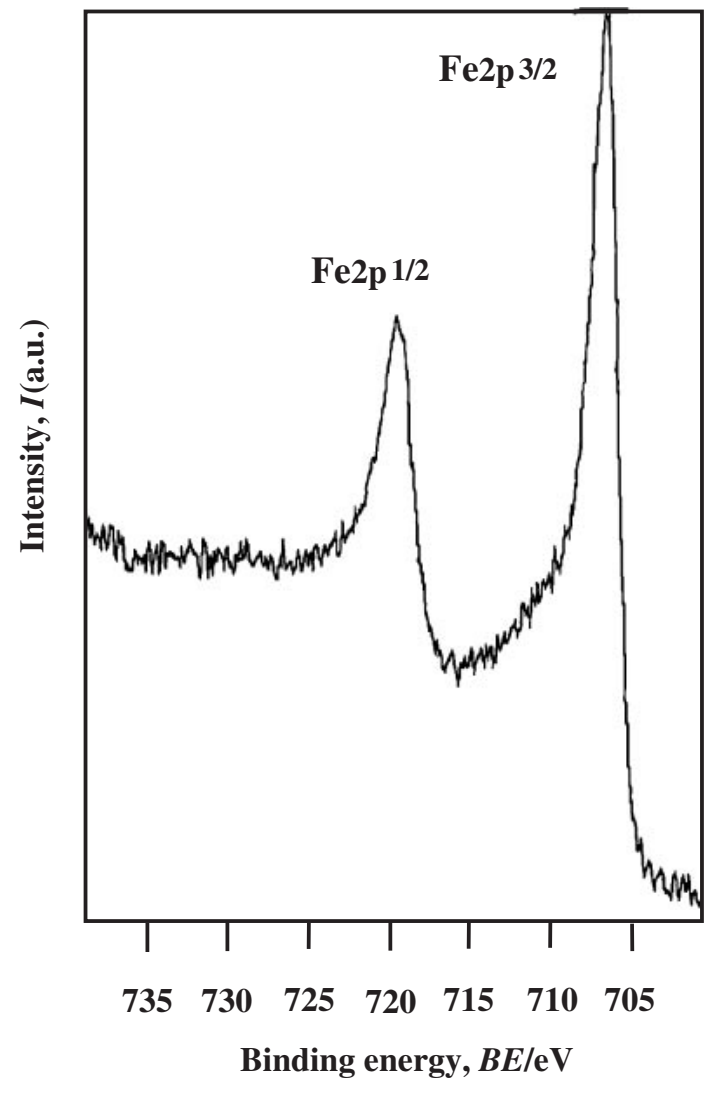

Fig. 10 XPS spectrum of the center of the cross section in the LIPS compact prepared by sintering at $1523 \mathrm{~K}$ for $4 \mathrm{~h}$ with DP.

pressure rise and a large fluctuation in gas pressure appeared. This suggests that gas generation occurs during LIPS and VS.

According to the phase diagram, ${ }^{18)} \mathrm{FeO}$ is a stable phase at temperatures higher than $843 \mathrm{~K}$. Therefore, Fe oxide on the HSS powder surface is regarded as transformed into $\mathrm{FeO}$ at sintering temperature. The reaction between $\mathrm{FeO}$ and $\mathrm{C}$ in HSS powder (reaction I) is given by

$$
\mathrm{FeO}(\mathrm{s})+\mathrm{C}(\mathrm{s})=\mathrm{Fe}(\mathrm{s})+\mathrm{CO}(\mathrm{g}),
$$

where the symbol (s) indicates a solid state, the symbol (g) indicates a gas state. Since evacuation is continuously carried out during sintering, LIPS and VS are regarded as open system. When the reaction I progresses during LIPS and VS, the partial pressure of $\mathrm{CO}$ gas is given as

$$
\log \left(P_{\mathrm{CO}}\right)<-\Delta G_{\mathrm{I}}{ }^{\mathrm{o}} / 2.303 R T,
$$

where $P_{\mathrm{CO}}, \Delta G_{\mathrm{I}}{ }^{\circ}, R$ and $T$ are the partial pressure of $\mathrm{CO}$ gas, standard free energy for the reaction I, gas constant and sintering temperature, respectively. On the other hand, The reaction between $\mathrm{Fe}$ in $\mathrm{HSS}$ powder and $\mathrm{O}_{2}$ gas in stainlesssteel pipe (reaction II) is given by

$$
\mathrm{Fe}(\mathrm{s})+1 / 2 \mathrm{O}_{2}(\mathrm{~g})=\mathrm{FeO}(\mathrm{s}) .
$$

In an open system, when the reaction II progresses during LIPS and VS, the partial pressure of $\mathrm{O}_{2}$ gas is given as

$$
\log \left(P_{\mathrm{O}_{2}}\right)>-\Delta G_{\mathrm{II}}{ }^{\mathrm{o}} / 0.868 R T,
$$

where $P_{\mathrm{O}_{2}}$ and $\Delta G_{\mathrm{II}}{ }^{\circ}$ are the partial pressure of $\mathrm{O}_{2}$ gas, standard free energy for the reaction II, respectively.

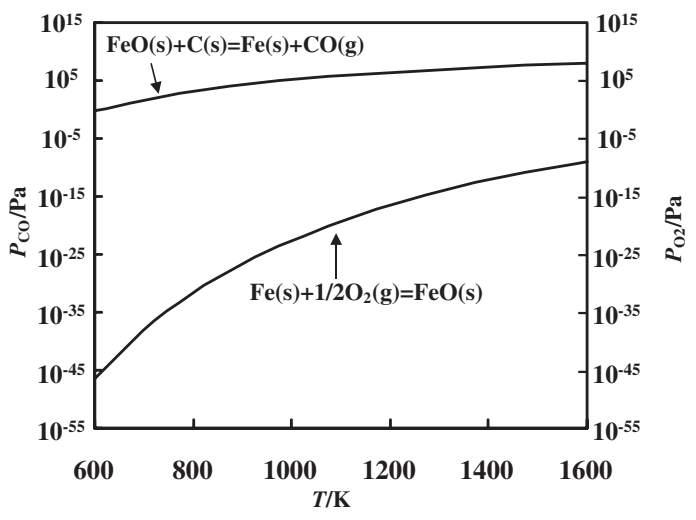

Fig. 11 Relationships between partial pressure of gas and sintering temperature.

Figure 11 shows the relationships between partial pressure of gas (Each standard free energy was obtained by HSC chemistry 5 in Outokumpu Research) and sintering temperature. Reaction I occurs under the partial pressure lower than the curve with respect to $P_{\mathrm{CO}}$, while reaction II occurs under the partial pressure higher than the curve with respect to $P_{\mathrm{O}_{2}}$. The gas pressure during LIPS and VS was about $2 \mathrm{~Pa}$ in the case of RP, about $2 \times 10^{-2} \mathrm{~Pa}$ in the case of $\mathrm{DP}$, respectively. It is noted from Fig. 11 that the reaction I is the governing factor at high sintering temperature in the case of both RP and DP. Evacuation with DP may promote reaction I as compared with that with RP. The result in which a remarked gas pressure rise and a large fluctuation in gas pressure appear at temperatures higher than $1473 \mathrm{~K}$ in the cases of LIPS and VS with DP is thought to be due to the generation of a large amount of $\mathrm{CO}$ gas with the reaction I. As the reaction I progresses, a cleaned surface of HSS powder is achieved by the decomposition of $\mathrm{FeO}$ film, resulting in high densification. Thus it is unnecessary to perform the usual pretreatment for reduction of oxide film on the iron powder in LIPS and VS with DP.

Figure 12 shows a schematic illustration of the LIPS mechanism. A gray part is HSS powder. The outer black part is Fe oxide. At a relatively low sintering temperature $(1473 \mathrm{~K})$, the degree of powder contact is low because powder deformation occurs only slightly owing to the high strength of HSS powder. In the case of LIPS with RP, the decomposition of $\mathrm{FeO}$ film is not vigorous, resulting in low densification. On the other hand, the decomposition of $\mathrm{FeO}$ film is vigorous in the case of LIPS with DP, resulting in high densification. At a higher sintering temperature $(1523 \mathrm{~K})$, sinterability is promoted by the following behavior; (1) the decomposition of $\mathrm{FeO}$ film is vigorous, (2) the degree of powder contact increases because a large plastic flow of powder particles occurs owing to both the degradation of the strength of HSS powder and the compression stress caused by atmospheric pressure, and (3) Fe diffusion is encouraged. In VS without pressing, behavior (2) cannot occur though the behavior (1) and (3) can take place. This may result in the VS compact which has not only a large cavity but also lower hardness and higher porosity as compared with the LIPS compact. Thus, under optimum LIPS conditions, it is possible to obtain a good 


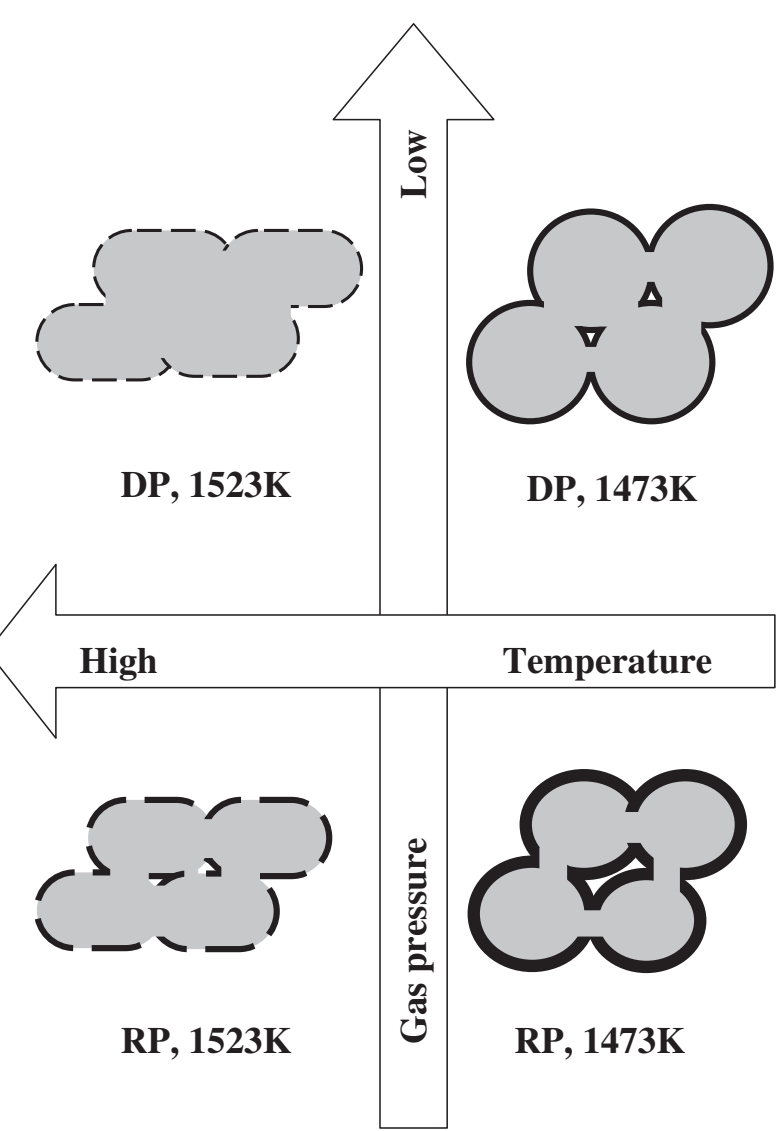

Fig. 12 Schematic illustration of the LIPS mechanism.

sintered compact which has porosity and hardness levels equivalent to those of the HIP compact.

Figure 13 shows the hardness distribution of the cross section of the LIPS compact prepared by sintering at $1523 \mathrm{~K}$ with DP. In the hardness distribution along the radial direction (Fig. 13(a)), the hardness is constant $\left(H_{\mathrm{v}} 460\right)$ from the surface to the center. In the case of LIPS for $4 \mathrm{~h}$, the hardness of the center of the LIPS compact rises, while the hardness near the surface drops off. In the case of LIPS for $8 \mathrm{~h}$, the hardness of the center of the LIPS compact is similar to that in the case of LIPS for $4 \mathrm{~h}$, but the hardness near the surface is higher than that in the case of LIPS for $4 \mathrm{~h}$. These results may be considered as follows:

(1) in the case of LIPS for $1 \mathrm{~h}$, the sintering is regarded as the early stage of sintering, resulting in the existence of a few pores (Fig. 8) and relatively low hardness $\left(H_{\mathrm{v}} 460\right)$.

(2) in the case of LIPS for $4 \mathrm{~h}$, the densification of the center of the LIPS compact is accelerated by the stimulation of Fe diffusion (Fig. 4(d)), resulting in high hardness $\left(H_{\mathrm{v}} 550\right)$. According to the densification of the center of the LIPS compact, the pores diffuse into the surface. Therefore, many pores exist near the surface, resulting in the reduction of the hardness near the surface.

(3) in the case of LIPS for $8 \mathrm{~h}$, because Fe diffusion further promoted, a high-densification region having high hardness $\left(H_{\mathrm{v}} 550\right)$ spreads towards the surface and also the hardness near the surface rises. By holding for a larger period, it may be possible to obtain the LIPS compact that exhibits uniform hardness from the surface to the center.
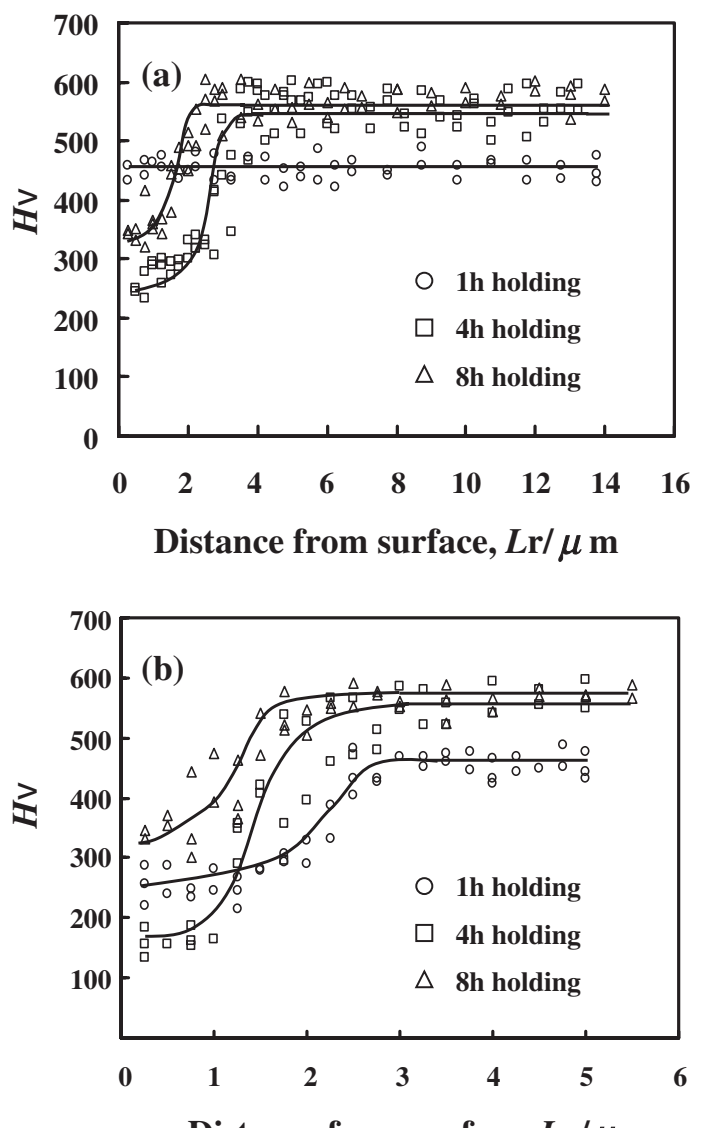

Distance from surface, $L \mathrm{a} / \mu \mathrm{m}$

Fig. 13 Hardness distribution of the cross section of the LIPS compact prepared by sintering at $1523 \mathrm{~K}$ with DP. (a) radial direction, (b) axial direction.

In the hardness distribution along the axial direction (Fig. 13(b)), the hardness distribution is similar to that along the radial direction, except for the reduction of hardness near the surface of the LIPS compact prepared by holding for $1 \mathrm{~h}$. By holding for a larger period, it may be possible to obtain the LIPS compact that exhibits uniform hardness along the axial direction.

As mentioned above, under optimum LIPS conditions, it may be possible to obtain a homogeneously sintered compact which has porosity and hardness levels equivalent to those of a HIP compact. This suggests that isostatic pressing due to atmospheric pressure contributes greatly to the production of a homogeneous LIPS compact.

\section{Conclusion}

An end-sealed thin stainless-steel pipe in which a highspeed steel green compact was inserted was evacuated with a vacuum pump during heating at an elevated temperature using an atmosphere furnace. From the results of this low isostatic press sintering (LIPS), the following conclusions were obtained.

(1) The green compact is subjected to isostatic compression stress through the deformation of stainless-steel owing to atmospheric pressure.

(2) As the gas pressure in the stainless-steel pipe is low, as 
the sintering temperature is high, and as the holding time is long, densification and hardness of the LIPS compact are large. This is because the decomposition of $\mathrm{FeO}$ film formed on the surface of the as-received powder is vigorous at a lower gas pressure in the stainless-steel pipe and a higher sintering temperature, the degree of powder contact increases because of a large plastic flow of powder particles owing to both the degradation of the strength of high-speed steel powder at a high temperature and the compression stress caused by atmospheric pressure, and Fe diffusion is encouraged by heating at a high temperature for a long time.

(3) At an early stage of LIPS, pores of the center of the LIPS compact diffuse into the surface, resulting in low densification near the surface. However, by holding for a long time, the LIPS compact that has high densification from the surface to the center is obtained because of encouragement of Fe diffusion.

(4) Under optimum LIPS conditions, it is possible to obtain a homogeneous LIPS compact which has porosity and hardness levels equivalent to those of the HIP compact.

\section{Acknowledgement}

This study was administrated through Nippon Steel Co. as a part of Energy Saving Projects with funding from Ministry of Economy, Trade and Industry of Japan.

\section{REFERENCES}

1) Y. Kimura, Y. Mishima, S. Umekawa and T. Suzuki: J. Mater. Sci. 19 (1984) 3107-3114.

2) H. Liu, U. Madaleno, T. Shinoda, Y. Mishima and T. Suzuki: J. Mater. Sci. 25 (1990) 4247-4254.

3) P. B. Maxwell, G. P. Martins, D. L. Olson and G. R. Edwards: Metall. Mater. Trans. B 21B (1990) 475-485.

4) S. Abraham, B. C. Pai and K. G. Satyanarayana: J. Mater. Sci. 27 (1992) 3479-3486

5) S. G. Wrrier, C. A. Blue and R. Y. Lin: J. Mater. Sci. 28 (1993) 760768.

6) A. R. Chapman, S. M. Bleay and V. D. Scott: J. Mater. Sci. 29 (1994) 4523-4534.

7) Y. Yasutomi: Bulletin Japan Inst. Metals 37 (1998) 234-237.

8) K. Okamura, T. Shimoo and T. Seguchi: New Ceramics 11 (1995) 1-6.

9) M. Mizumoto, T. Hanaoka, H. Miyahara and K. Ogi: J. Japan Inst. Metals 63 (1999) 1304-1310.

10) K. K. Lee, C. S. Kang and D. J. Lee: J. Japan Inst. Metals 64 (2000) 2733.

11) P. G. Partridge and C. M. Ward-Close: Int. Mater. Rev. 38 (1994) 1-24.

12) H. E. Deve: Metall. Mater. Trans. A 30A (1999) 2513-2522.

13) T. Yamada, T. Tsuzuki and H. Sato: J. Japan Inst. Metals 65 (2001) 946-954.

14) H. Sueyoshi, T. Maruno, K. Yamamoto, Y. Hirata, S. Sameshima, S. Uchida, S. Hamauzu and S. Kurita: Mater. Trans. 43 (2002) 735-740.

15) H. Sueyoshi, T. Maruno, M. Asano, Y. Hirata, S. Sameshima, S. Uchida, S. Hamauzu and S. Kurita: Mater. Trans. 43 (2002) 28662872.

16) F. R. Dax: Metal Powder Report 38 (1983) 200-202.

17) Japan Inst. Metals: A Data Book on Metals, (Maruzen, Tokyo, 1974) p. 25.

18) ASM International: ASM Handbook Vol. 3 Alloy Phase Diagrams, (ASM International, Ohio, 1992) p. 2-199. 